\title{
Smart Meter Solution for Developing and Emerging Economies
}

\author{
A. E. Ibhaze1, *, M. U. Akpabio², and A. A. A. Atayero \\ ${ }^{1}$ University of Lagos, Akoka, Yaba, Lagos, Nigeria \\ ${ }^{2}$ Covenant University, Ota, Ogun State, Nigeria \\ (Received 05 July 2017; Accepted 5 September 2017; Published on line 1 September 2018) \\ *Corresponding author: eibhaze@unilag.edu.ng \\ DOI: 10.5875 /ausmt.v8i3.1529
}

\begin{abstract}
Emerging economies are an increasingly significant part of the global market, and the potential for technology integration and innovation in such areas cannot be overstated. Smart electrical meters are a key component for monitoring and controlling energy consumption, but the installation of such meters assumes the existence of basic smart infrastructures. This paper, however, focuses on the use of home-based smart meters to allow for the remote switching of loads to achieve energy conservation. The design of a smart metering infrastructure coupled with load control capabilities is presented, achieving effective energy management with built-in load control. When deployed, this metering architecture will promote efficient home energy management.
\end{abstract}

Keywords: Load control; smart circuit breaker; smart grid; smart meter; home area network

\section{Introduction}

The emerging future of connected communities demands an intelligent interconnection of infrastructure, energy, technology and human activities. Energy availability and efficiency is a key determinant of national and global activities. A key difference between renewable and sustainable energy sources is that the former is human-made, while the latter is not [1]. This implies that renewable energy sources like biogas require the growth, consumption and disposal of organic materials for its generation. Sustainable energy, on the other hand, is an ambiguous term that has to do with the extension of the life expectancy of renewable energy sources. Conversely, without loss of generality, renewable energy sources are sources that will naturally replenish themselves despite human energy extraction, while sustainable energy is defined in terms of a definable period of availability.

While a key focus of "smart city" developments centers on the further development of green energy sources, harmonizing the energy generated from such sources - i.e., creating a "Smart Grid" - is an increasing area of research and commercial interest [2] [3]. Smart grid development requires synchronizing various energy sources to provide electricity at rated voltages and frequencies. Depending on specific regional characteristics, effective energy distribution depends not only on the proper use of smart grid technology, but also on smart metering and seamless wireless communications infrastructure.

Smart meters are a type of intelligent electronic device with built in communications capabilities used for power grid measurement [4]. Trends in the design and integration of such devices have evolved from power management, a major concern to the utility organizations, to demand-side management, a concern for energy consumers [5]. This trend in energy meter development is a key Smart Grid component referred to as Advanced Metering Infrastructure (AMI) [6], which integrates communications infrastructure, data analytics and enduser metering terminals. The devices responsible for the metering operations are called Smart Meters (SM), used to establish a 2-way communication between energy consumers and suppliers [6]. SMs allow for efficient energy management through Demand Side Management (DSM) [7], which refers to practices consumers can adopt to use energy more efficiently. These practices include 
switching off home appliances when they are not in use and shifting critical power tasks to non-peak periods. An SM helps the consumer understand the load consumption of individual appliances and can also serve as a platform for load control, even when away from home, thus significantly improving energy conservation. The authors in [8] proposed a smart meter model that manages billing and other cost-related functions while [9] asserted that old traditional prepaid meters could be refurbished and made intelligent at a lower cost than producing and deploying new prepaid meters [10]. Using IC ADE7753 as an analog device allows for the inexpensive transmission of data via the Serial Peripheral Interface (SPI). It performs most of the power calculations while also identifying power outages, over current, etc. This functionality allows the ADE7753 to send interrupt signals to the base station in the event of tampering [11]. Its limited pulsating time enables the interfaced Arduino to save the measurement data on an SD card. This allows the IC to communicate with external devices without the measurement process being disturbed [12]. The provision for an SD card slot is important as it allows the meter to store metering data while providing periodical (i.e., monthly or annual) reports for overall energy consumption and consumption of individual appliances. This paper focuses on the integration of Smart Demand-Side Management (SDSM) and Smart Utility Management System (SUMS) functionality in the smart meter architecture.

\section{Functionality of a Cost Effective Smart}

Augustus Ehiremen Ibhaze is presently a Lecturer in the Department of Electrical and Electronics Engineering, University of Lagos, Akoka, Lagos, Nigeria. He previously served as a Lecturer in Covenant University and he holds an MSc in Electrical and Electronics Engineering from the University of Lagos (2012) where he graduated with a distinction and BEng (Hons) in Electrical Engineering from Ambrose Alli University, Ekpoma, Nigeria, in 2008. He holds a Professional Certification in Information Technology service management (ITILversion3), Netherlands. He was elected as a Corporate Member of the Nigerian Society of Engineers and is a registered Engineer with the Council for the Regulation of Engineering in Nigeria (COREN).

Email: eibhaze@unilag.edu.ng

Moses Uwakmfon Akpabio is a graduate of Covenant University, Ogun State, Nigeria. He has spent some time in the power sector working in the Transmission Company of Nigeria (TCN) and also at Teshmont-Derekson consortium; which is a consulting company with its major competency being in Electrical Power. His research interests involve electrical power with emphasis on the smart grid. He is currently in pursuit of a Masters in Electrical Engineering.

Email: mosesuwak111@gmail.com

Aderemi A. Atayero is currently the Vice Chancellor of Covenant University and a Professor of Communication Engineering in Covenant University, Ota, Ogun state, Nigeria. He is a recipient of various awards and scholarships including the 2009 Ford Foundation Teaching Innovation Award'. His current research interests are in various aspects of Communication Engineering, including: Wireless senor Networks, Wireless (Mobile) Communications, Internet of Things (ioT), and Smart Cities.

Email: atayero@covenantuniversity.edu.ng

\section{Meter}

For the Smart Meter to be successfully integrated into the pre-existing grid, the cost of implementation and installation must be low enough to incentivize consumers and utilities to replace existing prepaid meters.

Parameters for Developing Cost-Effective Smart Meters

The materials to be used in the development of the smart meter should be cheap but highly reliable and should preferably be implemented using free open source software to allow the meter source multiple data measurements.

The SM must be designed to allow easy, plug-andplay installation such that it can serve as both a power meter and a tool for analyzing consumption by individual electrical devices.

The data collection function should be able to collect data over both short and long periods of time, thus providing better insight into household energy consumption while assisting load flow calculation and power system monitoring.

The meter should be able to store measured data over long periods. This is useful especially in long term planning and analysis as this data can reflect trends in power consumption.

Online data collection is useful especially in the execution of state estimation which helps in analyzing the state of the power system. An algorithm is implemented to minimize measurement errors, filtering out both systematic and randomly imposed errors.

An intuitive and flexible graphical user interface (GUI) enables non-technical users to easily interact with the smart meter.

\section{Benefits of Using Smart Meters}

The increasing deployment of smart meters in developing economies will lead to the seamless integration of flexible green technologies such as renewable energy sources. Consumers will be able to monitor their energy consumption while the utility operatives will be better equipped to efficiently monitor and manage energy consumption.

Data collection by smart meters will enhance the quality of energy consumption impact assessment, contributing to the development of green environmental initiatives and accelerating the green energy revolution [13]. As part of the impact assessment for smart metering, [14], proposed energy consumer behavior change as a key driver of improved energy conservation. According to the study carried out in [14], evaluating consumer behavior change at peak demand periods will flatten load profiles and thus reduce the incidence of blackouts. 
Energy pricing will be strictly based on a per use case scenario as opposed to the traditional method of splitting tariffs into peak and off-peak periods with a varying pricing schedule [15] and evaluating billing based on estimates. The authors in [16] conducted an investment analysis on smart meters and justified the financial cost savings despite energy savings as billing is done based on actual energy consumption. Among other benefits is reliable access to energy data for consumers and utility management. The implementation of high performing algorithms in smart meters will assist in real-time energy consumption measurement, power quality initiatives (power quality monitoring, data availability and management etc.) and energy tampering detection [17] [18], among others.

\section{Components of the Smart Metering System with Load Control}

As shown in Fig. 1, the smart meter consists of four seamlessly interacting modules: Metering module, Control module, Communication module and Display module.

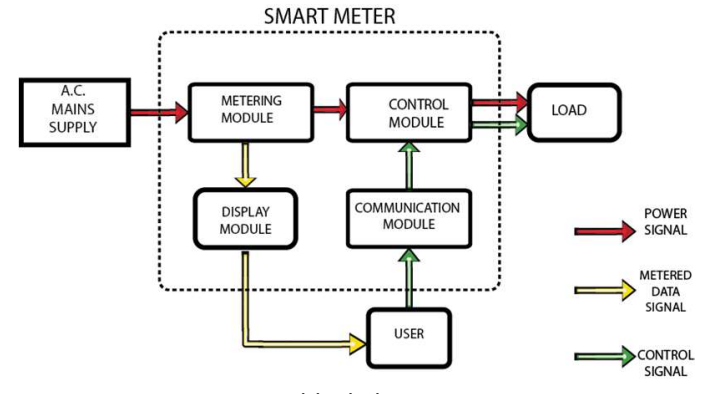

Fig. 1. Smart metering system block diagram.

\section{The Metering Module}

The essential function of a smart meter is to measure the amount of energy consumed by the connected loads. The meter performs this function by collecting data from the AC (Alternating Current) mains supply. A current sensor senses the $A C$ from the mains supply as shown in Fig. 2.

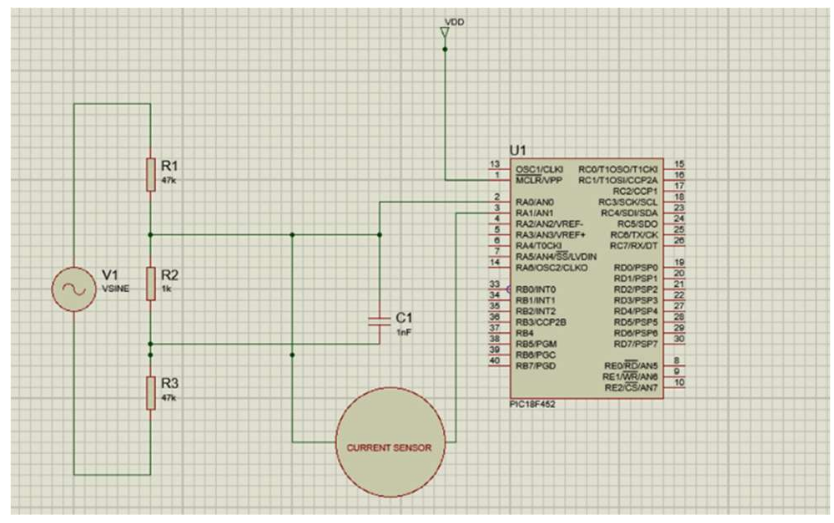

Fig. 2. Schematic diagram of the metering module of the smart meter.
The current sensor acts as a transducer as it converts the analog $A C$ current to a form (digital or analogue) that can be read by the Analog-Digital Converter (ADC) pin of the PIC. The output of the current sensor is an analogue signal whose amplitude is proportional to the magnitude of the current being measured. Before the current reading is inputted into the PIC, it has to first pass through a series of resistors as shown in Fig. 2. The arrangement of resistors performs two functions. First, it calculates the voltage across the terminals (i.e., the voltage between the Live and Neutral wires) based on Eq. (1)

$$
V=I * R
$$

Where $I$ is the current flowing through the wire and $R$ is the resistance value of the burden resistor. The second function of the resistor arrangement is to act as a voltage divider to reduce the amount of voltage entering into the circuit as shown in Eqs. (2) - (4).

The maximum input voltage that the PIC18F542 can accommodate is $5 \mathrm{~V}$. Since the meter is to be connected directly to the mains, in Nigeria the voltage entering the meter is between $230 \mathrm{~V}-240 \mathrm{~V}$ as stipulated by the electrical utilities [35]. The voltage then needs to be stepped down to $5 \mathrm{~V}$ without the use of a transformer through applying the voltage divider rule. The ratio of the voltages is given by:

$$
\begin{aligned}
& 5 / 240 \\
& 1 / 48
\end{aligned}
$$

According to Eq. (3), the voltage divider should be such that the ratio of the resistor complements the voltage ratio. Eq. (3) can be rewritten as;

$$
1 /(23.5+1+23.5)
$$

Equation (4) shows the optimum resistor arrangement to obtain $5 \mathrm{~V}$ from 220V. Due to market availability, $23.5 \mathrm{k} \Omega$ was replaced by $47 \mathrm{k} \Omega$ resistor and 1 was represented by a $1 \mathrm{k} \Omega$ resistor. The resultant voltage divider is shown in Fig. 3 and analyzed in Eqs. (4) - (6).

$$
\begin{gathered}
V=1 /(47+47+1) \times 240 \mathrm{~V} \\
V=0.01052 \times 240 \mathrm{~V} \\
\therefore V=2.5248 \mathrm{~V}
\end{gathered}
$$

As seen from Eq. (6), the voltage entering the PIC is $2.5248 \mathrm{~V}$. This voltage is safe enough to operate the PIC 
(since it is lower than the maximum input voltage, 5V) and still allow it to perform its metering function. The PIC acts as the Microcontroller Unit (MCU) of the Smart Meter, implementing the main metering operations. The code is basically a set of instructions that tells the PIC the data to collect and manipulate the given data to provide the required output, in this case is the energy in Kilo-Watthour as well as the voltage level from the mains and the current drawn by the load.

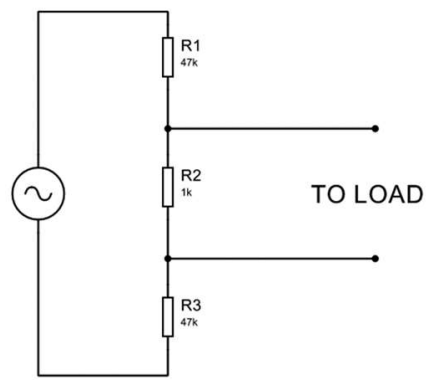

Fig. 3. Schematic diagram of the metering module of the smart meter.

The voltage ratio shown in Eq. (4) establishes the range of voltage values to be manipulated within the PIC, with $2.5248 \mathrm{~V}$ corresponding to the maximum expected voltage, $240 \mathrm{~V}$, and $\mathrm{OV}$ being the minimum in both instances. The current drawn by any load is a function of the power consumed by the load. Since the ideal voltage is assumed to be constant at $240 \mathrm{~V}$, the current drawn can be obtained from the power rating [19], given by;

$$
P=V I
$$

where I is the current drawn by the device in amperes and $\mathrm{V}$ is the applied voltage (usually $240 \mathrm{~V}$ in Nigeria).

The energy can therefore be calculated by multiplying the power by a time factor, giving the energy in Kilo-Watt-hour KWh.

$$
E=I x V x T
$$

where $\mathrm{E}$ is the energy in $\mathrm{KWh}, \mathrm{I}$ is the current in amperes, $V$ is the voltage in volts and $T$ is the time in hours.

The PIC exports the calculation results to a display. The metering PIC has 40 pins. Although some pins have definite functions (such as Vdd for input voltage and Vss for output voltage), any of the other unassigned pins can be used to connect the PIC to the LCD provided they are correctly identified in the PIC sketch. Once the code is properly loaded and all relevant pins correctly assigned and identified, the PIC should be able to use to current flowing through the mains and the current drawn by the load to calculate the energy consumed by the load and display the data on the chosen display device.

\section{The Display Module}

A display module is required to provide two-way communication between the utility provider and the consumer. This is a major improvement on the traditional prepaid meter which only allowed the utility provider access to metered data. Diverse display devices that can be used for the display module of a smart meter includes LED and LCD screens. The display module used for this prototype is a blue 1602 LCD screen. It has 2 lines each of which can accommodate 16 characters, sufficient for the required display parameters. It has 16 pins; pins 7-10 are for low-order bidirectional data exchange between the Microcontroller unit (MCU) and the LCD, however, these four pins are not used for 4-bit operation. Pins 11-14 are for high order data exchange and can be used for 4-bit operations. Any of these pins (11-14) can be used to transfer the required data from the MCU. Pins 1 and 2 (Vss and $\mathrm{Vdd}$ ) of the LCD are for the power supply. The LCD's maximum and minimum voltages are respectively $7 \mathrm{~V}$ and $-0.3 \mathrm{~V}$. As established in Eq. (7), the voltage in this metering circuit is $2.5248 \mathrm{~V}$ which is well within the prescribed range. Therefore, the LCD is sufficiently supplied with voltage. Pins 4-6 are used for specific command signals; pin 4 (RS) is used to select the register from the MCU, pin $5(R / W)$ is used to choose between reading or writing to the selected register. Pin $6(E)$ is used to enable the selected operation i.e., read or write. After performing all the necessary calculations, the PIC sends the metered data to the LCD via pins 11-14. Since only three parameters were measured (voltage, current and energy), only 3 pins are required for operation. Once these pins have been properly assigned and identified in the code loaded into the PIC, the meter data should be properly displayed on the LCD. The diagram showing the connection between the MCU and the LCD is shown in Fig. 4.

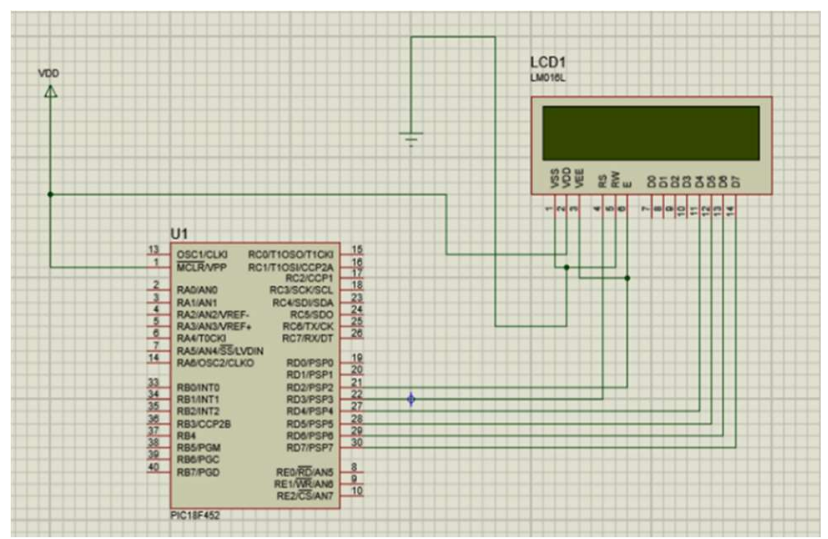

Fig. 4. Schematic diagram of the connection between the MCU and the LCD display.

Communication Module

Communication is one of the most important 
aspects of smart meter operation, and users can communicate effectively with their meters and other appliances via a Home Area Network (HAN). This is also very important when it comes to control, a key performance indicator for smart home integration [20]. There are a number of network topologies that can be used to establish a HAN, including zigbee, wifi, Bluetooth, etc. The Bluetooth model was used in this design to model the communication pathway due to its ease of configuration with other devices since the majority of modern devices already come equipped with Bluetooth modules. This makes it easier to control the loads. However, Bluetooth suffers from an effective range of about $10 \mathrm{~m}$, which limits its effectiveness particularly for base station communication. The Bluetooth module has 6 pins, but only 4 are required for smart meter communication. The" key" and "state" pins are allowed to float. Positive voltage is connected to Vcc while GND is grounded. The receiver pin (Rxd) is connected to the transmitter (TX) of the PIC and the receiver of the PIC (RX) is connected to the transmitter of the Bluetooth module (Txd). This forms a communication loop which can be seen in Fig. 5. The full schematic diagram of the communication module is shown in Fig. 6. For wider coverage, wireless shield supporting wide area coverage could be used in place of the Bluetooth shield.

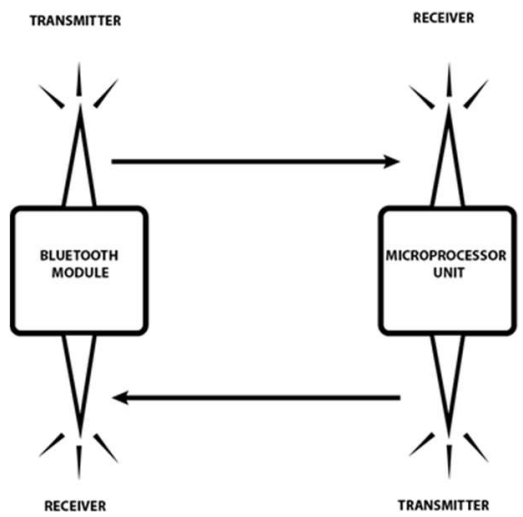

Fig. 5. Block diagram showing the communication pathway between Bluetooth and the MCU.

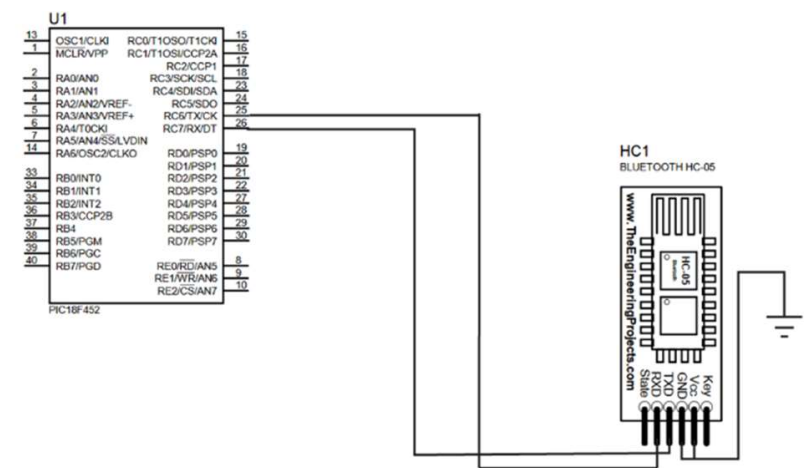

Fig. 6. Schematic diagram showing the connection between the Bluetooth with the MCU.

\section{Control Module}

The smart meter has an inbuilt control functionality which enables the user to remotely control the load without having to physically flip a switch. The aforementioned communication module is essential for this module to work as the communication channel is the medium through which the switching command can be delivered from the user to the load. A simple Android application was developed specially for this purpose. The application basically has five functions: First, search for nearby Bluetooth devices. Second, initialize scan for the Bluetooth module of the smart meter. Third, select the desired Bluetooth device from a variety of options. The Bluetooth address of the Smart Meter is configured as "HC-05" (as designated by the manufacturer) and should appear as such in the list of devices. For security reasons, the Bluetooth module requires a passport upon connection so as to prevent unlimited access by anyone in the user's home. Fourth, switch the load either ON or OFF and finally, disconnect from the Bluetooth device.

All these functions must be put in place in the mobile application for the control of the load via the smart meter. Once this is accomplished, the switching operation can take place. After the Android device has been successfully connected to the smart meter's Bluetooth module, it can send signals via the module to the MCU. When the application's "ON" command is triggered, a signal is sent to the Bluetooth module which then relays the command to the MCU. The MCU recognizes this command and then sends a $5 \mathrm{~V}$ output signal to the transistor. However, $5 \mathrm{~V}$ is too much for the transistor, and a resistor is connected in series between the MCU and the transistor. This causes a voltage drop across the resistor and the remaining voltage will be safe enough to enter the transistor. The voltage (which would exceed the emitterbase voltage, Vbe of the transistor, which is $0.7 \mathrm{~V}$ ) then triggers the transistor to energize the relay via the collector (since it is an NPN transistor that is to be used (i.e., the emitter is grounded). The load's positive terminal is connected to the common contact of the relay, while the positive contact from the mains is connected to the Normally Open (NO) contact of the relay. When the relay is energized, the common contact switches to the NO contact, thereby completing the circuit and energizing the load. When the "OFF" command is triggered on the Android application, the signal follows the same path and instructs the MCU to cut off the voltage supply to the transistor, thereby de-energizing the transistor and consequently the relay, meaning that the load would go OFF. The schematic diagram is shown in Fig. 7.

The final design involves interaction between all the functional modules. All these modules are combined to 
give the final smart meter design shown in Fig. 8.

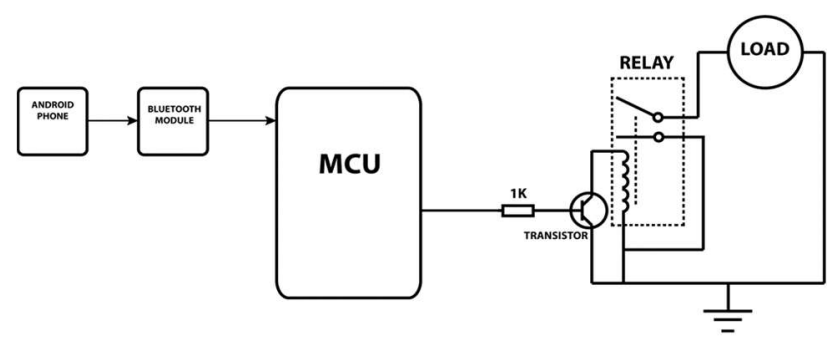

Fig. 7. Schematic diagram showing how the load is remotely controlled.

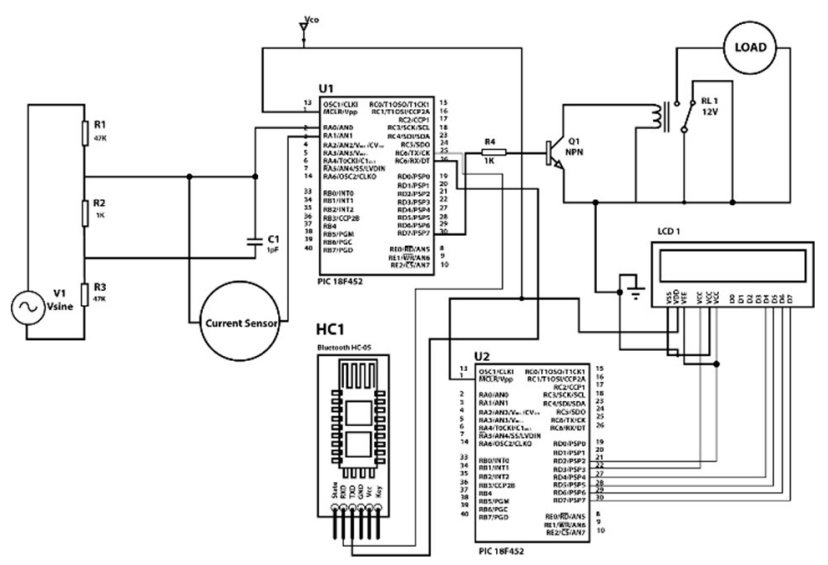

Fig. 8. Schematic diagram of the proposed smart meter.

\section{Smart Circuit Breakers (SCB)}

This is a relatively new concept which could have a tremendous impact on the future of smart metering and the Smart Grid. The SCB should be able to distinguish individual loads, whereas the conventional $C B$ take the loads as an aggregate and then trips them off accordingly. SCB provides flexibility for the monitoring and control of individual loads, offering control of other smart devices while performing other management services in case of emergencies.

\section{Smart Metering Prototype}

The smart metering prototype is developed through simulation and design implementation. Simulations were conducted using Proteus software, and provided a clear picture of the arrangement of rated components to arrive at a fully functional model. The simulations were carried out on the different modules individually and on the system as a whole. The simulation helped in identifying the exact components as well as their ratings and arrangement to be used to arrive at a fully functional model. The resulting circuit diagram of the final simulation is shown in Fig. 8 while the screenshot of the Proteus workspace is shown in Fig. 9.

The components were patched according to the circuit diagram on a bread board to obtain the first physical prototype of the metering system.

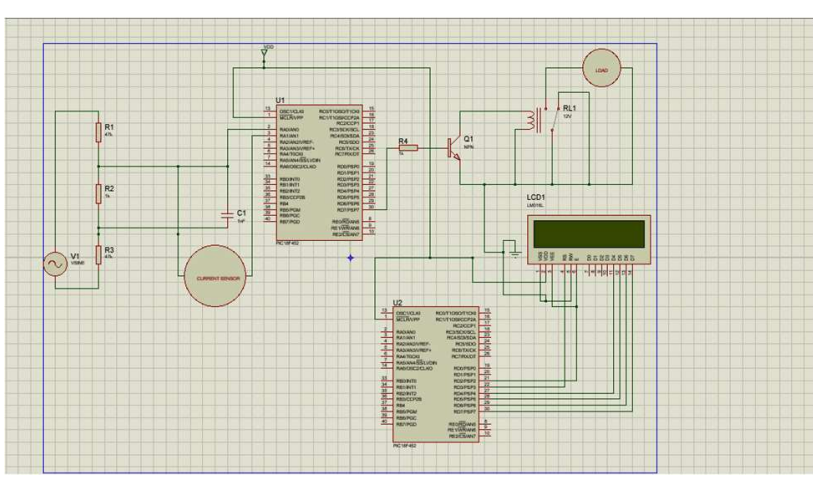

Fig. 9. Proteus Simulation Workspace.

The metering and communications modules were arranged on separate Vero boards as shown in Figs. 10 and 11 to allow for flexibility, especially in packaging.

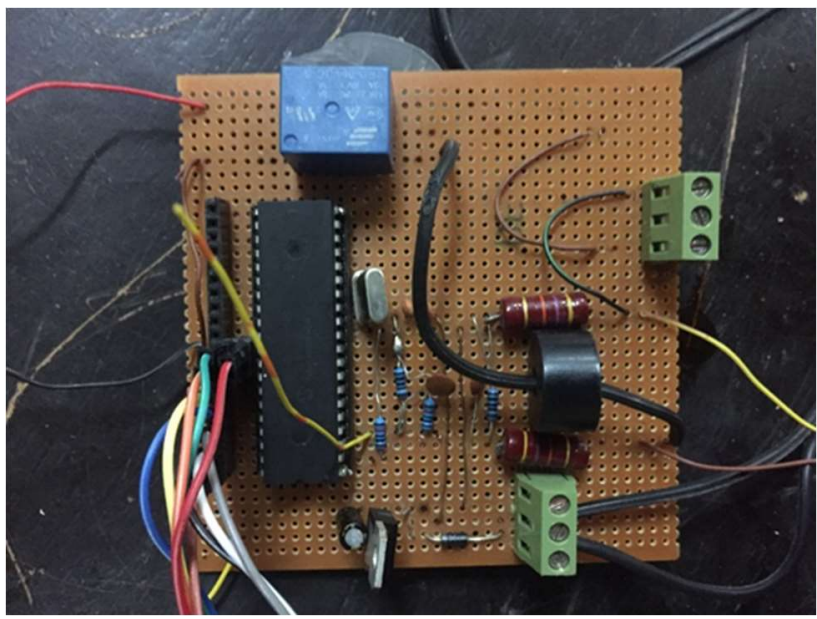

Fig. 10. Vero board model for the metering module.

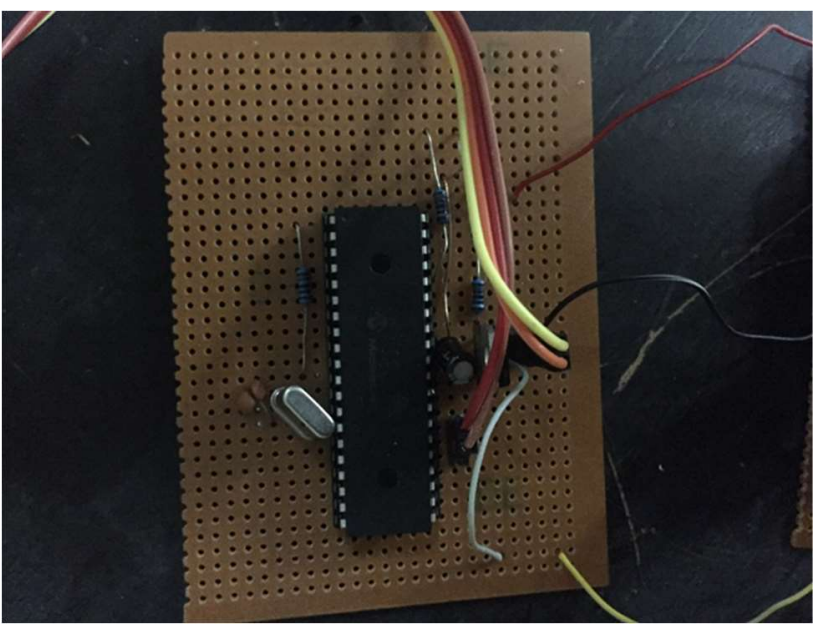

Fig. 11. Vero board model for the communication module.

A number of tests were conducted. Each of the smart meter modules were first tested individually to verify their functionality. The modules were then assembled together and tested as a complete unit. A 
number of appliances were connected to the meter output to simulate plugging an appliance into a house electrical outlet. The readings were recorded and crosschecked against manufacturer ratings. After tolerance was factored in, the meter produced desirable results as the displayed data was similar to the manufacturers rating.

Figure 12 shows the link between the Android application and the load to be controlled. The application was installed on a tablet PC and initialized. After initialization, the tab searched for available Bluetooth devices. As expected, the name "HC-05" popped up in the list of available devices. Once connection was established and the password inputted, the "ON" command was triggered causing the relay to trip. This tripping was accompanied by a clicking sound which was immediately followed by the lighting of the bulb connected as load. This process was carried out a number of times to ensure the process was functioning properly.

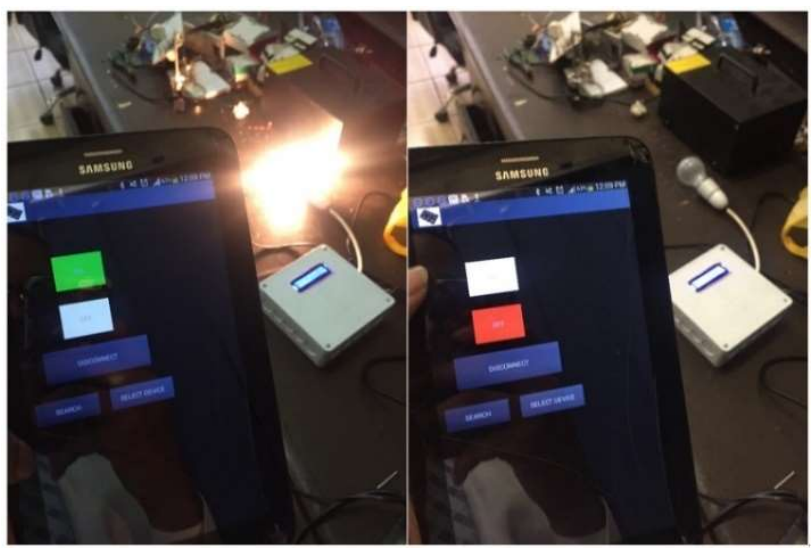

Fig. 12. Energizing and de-energizing of the load via the mobile app.

\section{Experimental Results}

The metering module was tested for its accuracy as shown in Fig. 13. The test platform was setup for about five (5) days in the laboratory.

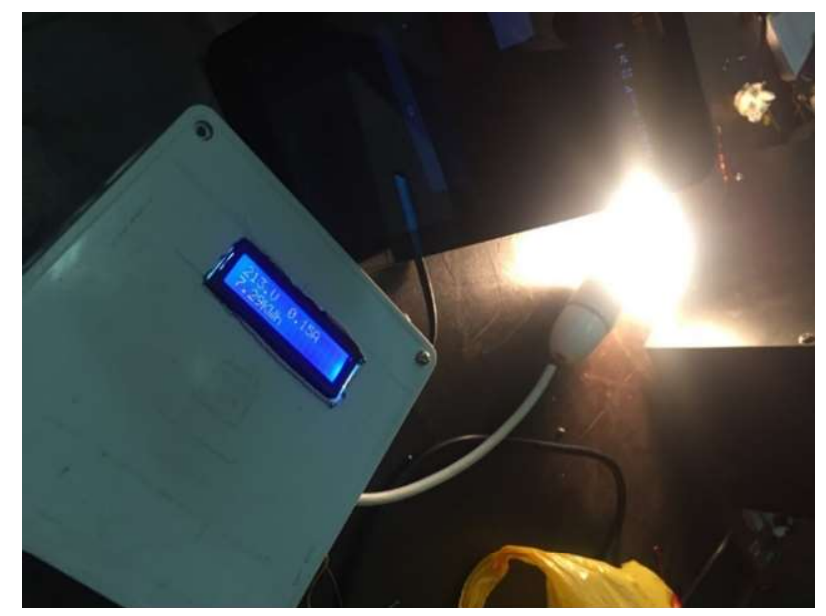

Fig. 13. Testing of the metering module.
The rated voltage is supposed to be $240 \mathrm{~V}$ but, due to losses along the line, $213 \mathrm{~V}$ was recorded as at the time of the experimental setup shown in Fig. 13. To validate the readings against theoretical estimates, Energy $E$ is given as the product of Power $\mathrm{P}$ and Time $\mathrm{t}$ given by;

$$
E=P t
$$

From the Smart meter readings, the Energy consumed in 5 days for a $60 \mathrm{~W}$ lamp was $7.29 \mathrm{kWh}$ and the load current was $0.15 \mathrm{~A}$.

From Eq. (10),

$$
\begin{aligned}
& 7.29 \mathrm{kWh}=60 \mathrm{~W} \cdot t \\
& t=7.29 \mathrm{kWh} / 60 \mathrm{~W}
\end{aligned}
$$

$t=7290 W h / 60 W=121.5$ hours $\approx 5.0625$ days

This validates the experimental setup as it ran for 5 days with a percentage difference of $1.25 \%$ due to calibration errors. Conversely, if a $25 \mathrm{~W}$ energy saving bulb was used, 7.29kWh would have been expended in 291.6 hours $\equiv 12.15$ days which could result in $140 \%$ increase in energy savings.

\section{Conclusion}

The development of smart and connected communities requires the efficient and reliable integration of intelligent technologies into existing infrastructure systems. This work presents a design framework for a smart meter based on existing meters, which allows for remote load control and identifying appliance-specific load consumption.

\section{Acknowledgment}

The authors gratefully acknowledge the sponsorship and funding of this project by Covenant University.

\section{References}

[1] S. Mohanty, U. Choppali, and E. Kougianos, "Everything you wanted to know about Smart Cities: The Internet of Things is the backbone," IEEE Consumer Electronics Magazine, vol. 5, no. 3, pp. 60-70, July 2016. doi: 10.1109/MCE.2016.2556879

[2] K. Vu, M. M. Begovic, and D. Novosel, "Grids Get Smart Protection and Control," IEEE Computer Apllications in Power, vol. 10, no. 4, pp. 40-44, 1997 doi: $\underline{10.1109 / 67.625373}$

ausMT Vol. 8 No. 3 (2018) 
[3] S. M. Amin and B. F. Wollenberg, "Toward a Smart Grid: Diversity for the 21st Century," IEEE Power and Magazine, vol. 3, no. 5, pp. 34-41, 2005. doi: 10.1109/MPAE.2005.1507024

[4] R. Lee, L.-L. Lai, and C.-S. Lai, "Design and Application of Smart Metering System for Micro Grid," in proceeding of IEEE International Conference on Systems, Man and Cybernetics, Manchester, UK, Oct. 13-16, 2013, pp. 3203-3207. doi: $10.1109 /$ SMC. 2013.546

[5] A. E. Ibhaze, M. U. Akpabio, and T. O. Akinbulire, "A review on smart metering infrastructure," Int. J. Energy Technology and Policy.

[6] D. Hart, "Using AMI to realize the smart grid," in proceeding of IEEE Power Energy Soc. Gen. Meeting Convers. Del. Electr. Energy 21st Century, Pittsburgh, PA, USA, July 20-24, 2008, pp. 1-2.

10.1109/PES.2008.4596961

[7] D. Alahakoon and X.-H. Yu, "Smart Electricity Meter Data Intelligence for Future Energy Systems: A Survey," IEEE Transactions on Industrial Informatics, vol. 12, no. 1, pp. 425-436, 2016. doi: $10.1109 /$ TII.2015.2414355

[8] J. Q. Azasoo and K. O. Boateng, "Smart Metering: A GSM approach in Ghana," in proceeding of IEEE 4th International Conference on Adaptive Science and Technology, Kumasi, Ghana, Oct. 25-27, 2012, pp. 158-163.

doi: 10.1109/ICASTech.2012.6381085

[9] "National Communications Authority Annual Report," Accra, Ghana, 2008.

[10] J. Q. Azasoo and K. O. Boateng, "A Retrofit Design Science Methodology for Smart Metering Design in Developing Countries," in proceeding of IEEE 15th International Conference on Computational Science and Its Applications, Banff, AB, Canada, June 22-25, 2015, pp. 1-7. doi: 10.1109/ICCSA.2015.23

[11] S. Ngamchuen and C. Pirak, "Smart Anti-Tampering Algorithm Design for Single Phase Smart Meter Applied to AMI Systems," in proceeding of IEEE 10th International Conference on Electrical Engineering/Electronics, Computer, Telecommunications and Information Technology, Krabi, Thailand, May 15-17, 2013, pp. 1-6. doi: 10.1109/ECTICon.2013.6559617

[12] A. Ellerbrock, A. Abdel-Majeed, and S. Tenbohlen, "Design and Building of a Cheap Smart Meter," Institute of Power Transmission and High Voltage Technology, Pfaffenwaldring 47, 70569 Stuttgart, Universität Stuttgart, Stuttgart.
[13] C.-M. Tung, "Growing trend of network-based, smart green buildings towards automatic energysaving performance: A study based on Advantech's energy-saving system," International Journal of Automation and Smart Technology, vol. 2, no. 2, pp. 75 - 77, 2012. doi: 10.5875 /ausmt.v2i2.150

[14] R. Hampshire, "Realising the benefits of smart metering: Creating consumer engagement," IET Smart Metering - Making It Happen, pp. 1 - 11, 2009.

[15] Q. M, Q.-Y. Ma, M.-H. Xu, R. Li, and F.-R. Li, "Quantitative benefit assessment of electricity settlement using smart meters," in proceeding of IEEE 13th International Conference on the European Energy Market (EEM), Porto, Portugal, June 6-9, 2016, pp. 1 - 4.

doi: 10.1109/EEM.2016.7521293

[16] L. Garpetun and P.-O. Nylén, "Benefits from smart meter investments," in proceeding of IEEE 22nd International Conference and Exhibition on Electricity Distribution (CIRED), Stockholm, Sweden, June 10-13, 2013, pp. 1 - 4. doi: $10.1049 / \mathrm{cp} .2013 .0837$

[17] M. Music, A. Bosovic, N. Hasanspahic, S. Avdakovic, and E. Becirovic, "Integrated power quality monitoring system and the benefits of integrating smart meters," in proceeding of IEEE International Conference-Workshop Compatibility and Power Electronics, Ljubljana, Slovenia, June 5-7, 2013, pp. $86-91$. doi: 10.1109/CPE.2013.6601134

[18] A. E. Ibhaze, M. U. Akpabio, and S. N. John, "A Review on Smart Grid Network Security Issues over 6LOWPAN," in proceeding of the Second International Conference on Internet of things and Cloud Computing (ICC'17), United Kingdom, March 22-23, 2017, pp. 180. doi: $10.1145 / 3018896.3056797$

[19] Y. V. Nazarov, "Generalized Ohm's Law," Quantum Dynamics of Submicron Structures, pp. 687-704, 1995.

[20] B. Andrés, F. Alejandra, J. Miguel, S. Augusto, and W. Pedro, "Towards the Evolution of Smart Home Environments: A Survey," International Journal of Automation and Smart Technology, vol. 6, no. 3, pp. 105 - 136, 2016 doi: $10.5875 /$ ausmt.v6i3.1039

[21] S. Finster and I. Baumgart, "Privacy-Aware Smart Metering: A Survey," IEEE Communications Surveys \& Tutorials, vol. 17, no. 2, pp. 1088-1101, 2015. doi: $\underline{10.1109 / C O M S T .2015 .2425958}$ 